\title{
lleo-ileal intussusception as an unusual cause of obscure overt gastrointestinal bleeding
}
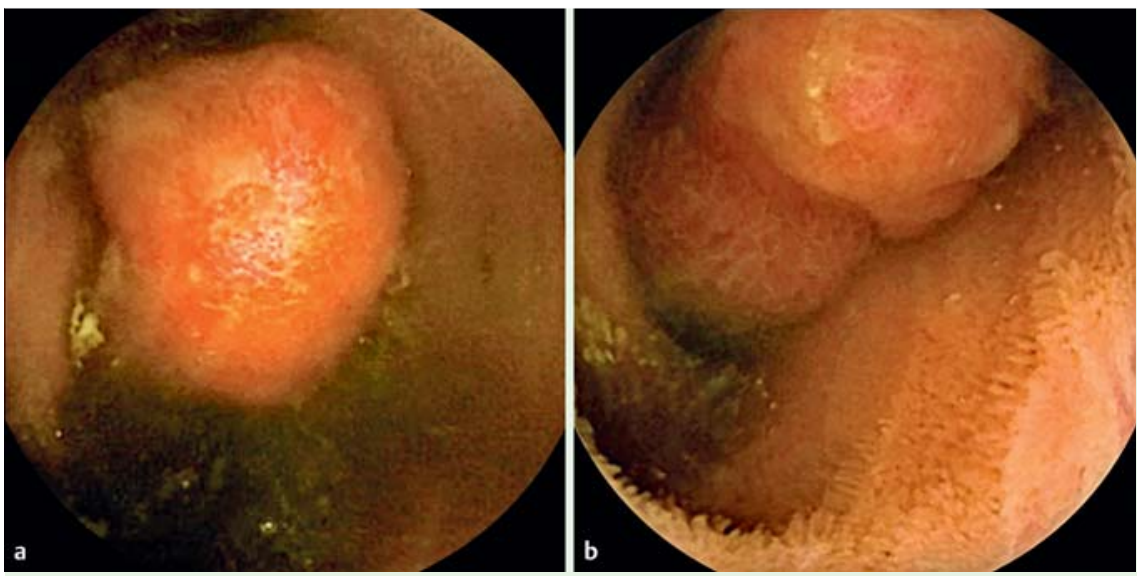

Fig. 1 Endoscopic appearance of a large polypoid formation in the proximal ileum with congested and ulcerated mucosa.

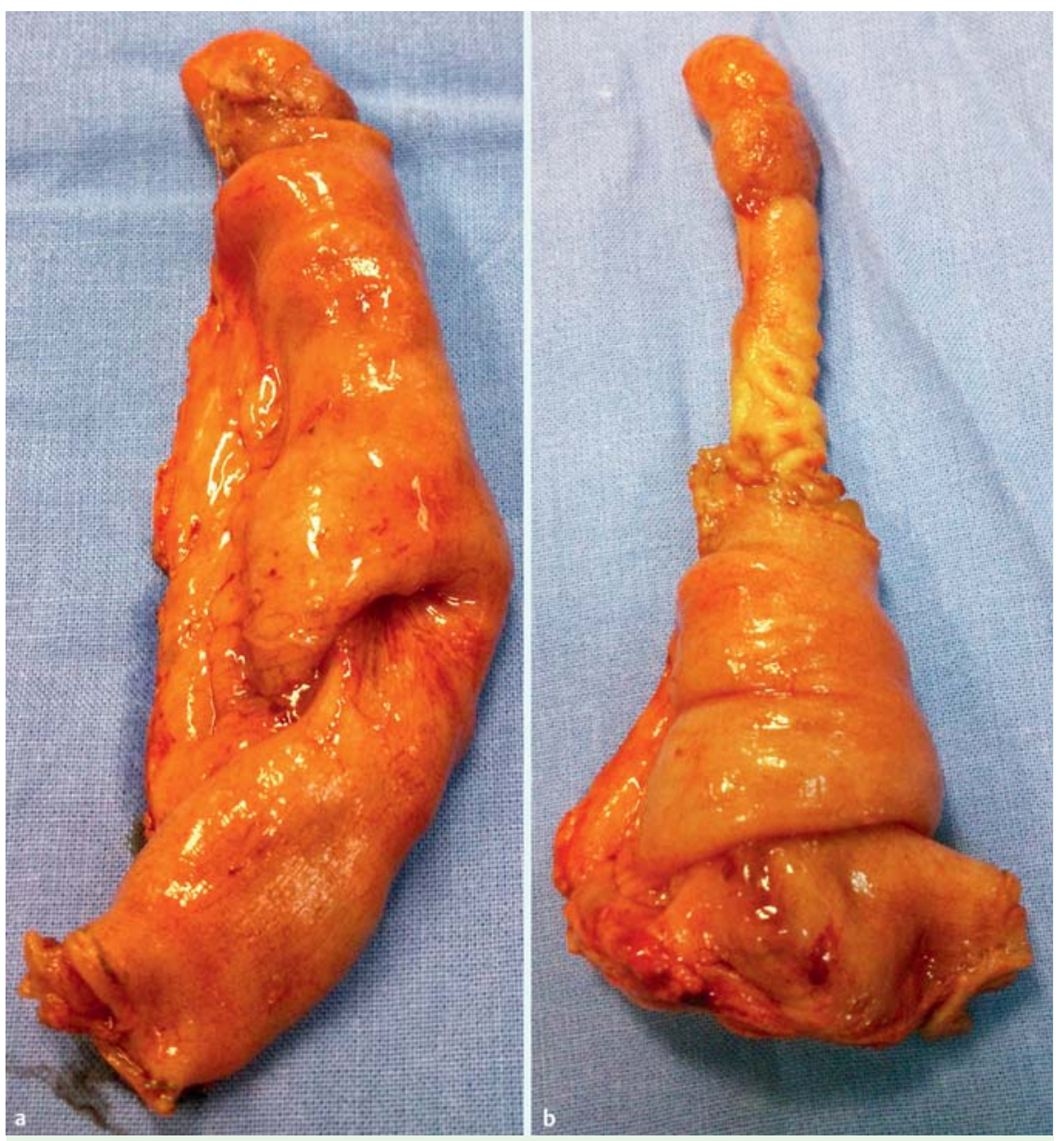

Fig. 2 The resected surgical specimen showing an ileo-ileal intussusception.

A 20-year-old man arrived at the emergency department with a 1-day history of melena and one episode of lipothymia. He had no medical history and was not taking any medication. Significant findings on physical examination included an arterial blood pressure of $90 / 40 \mathrm{mmHg}$, paleness of his mucosae and skin, and melena on rectal digital examination. Laboratory analysis revealed normocytic normochromic anemia $(6.7 \mathrm{~g} / \mathrm{dL})$ and an elevated urea level $(9.4 \mathrm{mmol} / \mathrm{L})$.

He was treated with fluid therapy and packed red blood cell transfusion. An upper gastrointestinal endoscopy was performed, which was normal. A colonoscopy with terminal ileoscopy showed the presence of blood in the colon and terminal ileum, without any mucosal changes. Scintigraphy with ${ }^{99 \mathrm{~m} T c-p e r t e c h n e t a t e}$ did not show any positive findings. A capsule enteroscopy identified a large polypoid formation with congested and ulcerated mucosa in the proximal ileum ( $\bullet$ Fig. 1; - Video 1), which caused a delay in capsule progression. Blood traces without active bleeding were identified.

The multidisciplinary team decided to perform an exploratory laparotomy. An ileal invagination in the proximal ileum was identified and a segmental enterectomy was performed

( $\bullet$ Fig.2). Macroscopic examination revealed an ileal invagination in the ileal lumen forming an intraluminal polypoid lesion of $7 \mathrm{~cm}$. Microscopic examination showed large necrotic areas and mucosal 


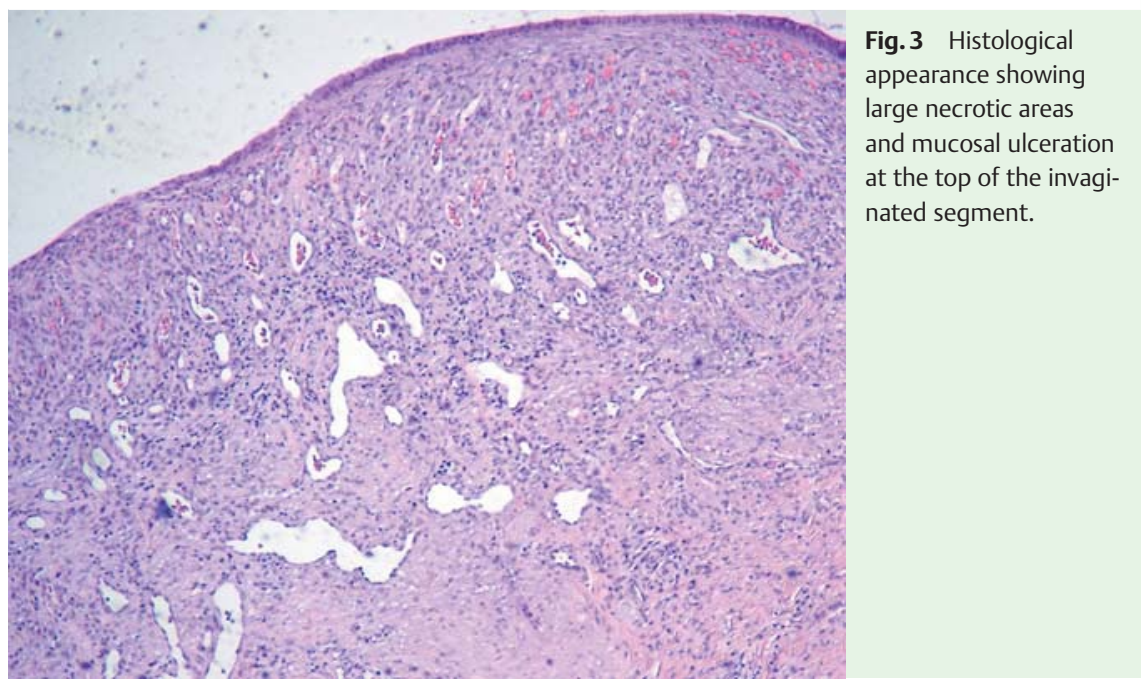

ulceration at the top of the invaginated segment ( $\bullet$ Fig.3). No tumor tissue was identified. The patient remained asymptomatic 1 year later.

Intussusception is a rare clinical condition in adults [1]. It may be secondary to intraluminal or extraluminal lesions [2], but $8 \%-20 \%$ of cases are idiopathic [3]. The majority of patients present with symptoms of bowel obstruction [4]. Intussusception is often misdiagnosed and the majority of cases are diagnosed intraoperatively [5]. We report a case of idiopathic ileo-ileal intussusception that presented with obscure overt gastrointestinal bleeding and emphasize the role of capsule enteroscopy, which allowed presurgical visualization of the lesion.

\section{References}

1 Lianos G, Xeropotamos N, Bali C et al. Adult bowel intussusception: presentation, location, etiology, diagnosis and treatment. G Chir Vol 2013; 34: 280-283

$2 \mathrm{Lu}$ T, Chng Y. Adult intussusception. Perm J 2015; 19: 79-81

3 Teixeira $D$, Martins $M$, Costa $V$ et al. Idiopathic bowel intussusception in adults: case report. Rev Port Cir 2013; 27: 107 - 112

4 Batista N, Maximiano LF. Intestinal intussusception in young adults - literature review. Rev Col Bras Cir 2009; 36: 533-536

5 Athanasios M, Anneza Y, Lazaros S et al. Intussusception of the bowel in adults: a review. World J Gastroenterol 2009; 15: 407 - 411

Bibliography

DOI http://dx.doi.org/

10.1055/s-0042-118230

Endoscopy 2016; 48: E386-E387

(c) Georg Thieme Verlag KG

Stuttgart · New York

ISSN 0013-726X

Competing interests: None

\section{Corresponding author}

\section{Catarina Atalaia-Martins, MD}

Catarina Atalaia-Martins ${ }^{1}$,

Sandra Barbeiro" ${ }^{1}$ Pedro Marcos ${ }^{1}$, Bruno Arroja ${ }^{1}$, Cláudia Gonçalves', Maria Fernanda-Cunha², Paulo Alves ${ }^{3}$

${ }^{1}$ Department of Gastroenterology, Centro Hospitalar Leiria, Leiria, Portugal Department of Gastroenterology Centro Hospitalar Leiria Rua das Olhalvas 2410-197, Leiria Portugal catarinatalaiamartins@gmail.com 